\title{
BMJ Open How does returning to work after retirement influence older workers' health? A scoping review protocol
}

\author{
Alexandra Lecours, ${ }^{1,2}$ Marie-Michèle Lord, ${ }^{3}$ Alessia Negrini, ${ }^{4}$ Rosalie Robitaille ${ }^{1,2}$
}

\begin{abstract}
To cite: Lecours A, Lord M-M, Negrini $A$, et al. How does returning to work after retirement influence older workers' health? A scoping review protocol. BMJ Open 2019;9:e026446. doi:10.1136/ bmjopen-2018-026446

- Prepublication history for this paper is available online. To view these files, please visit the journal online (http://dx.doi org/10.1136/bmjopen-2018026446).
\end{abstract}

Received 1 September 2018 Revised 22 February 2019 Accepted 25 February 2019

A Check for updates

C Author(s) (or their employer(s)) 2019. Re-use permitted under CC BY-NC. No commercial re-use. See rights and permissions. Published by BMJ.

1Département de réadaptation, Université Laval, Québec, Québec, Canada

${ }^{2}$ Center for Interdisciplinary Research in Rehabilitation and Social Integration, Québec, Québec, Canada

${ }^{3}$ Département d'ergothérapie, Université du Québec à TroisRivières, Trois-Rivières, Québec, Canada

${ }^{4}$ Institut de recherche RobertSauvé en santé et sécurité du travail, Montréal, Québec, Canada

Correspondence to Dr Alexandra Lecours; Alexandra.Lecours@fmed. ulaval.ca

\begin{abstract}
Introduction The return to the labour market after retirement is an increasing phenomenon in the North American population. It is the subject of a growing number of studies, whose conclusions seem inconsistent. As returning to working life after retirement is not neutral for individuals, the aim of this article is to present the protocol of a scoping review about its effects on older workers' health.
\end{abstract}

Methods and analysis The methodology of Arksey and 0'Malley, including the recommendations of Levac et al and Daudt et al will be used. The process is composed of seven steps, from the identification of the research question, to the planning of knowledge transfer activities. Documents dealing with retirees returning to work in connection with health will be explored and analysed using the International Classification of Functioning, Disability and Health.

Ethics and dissemination Approval has been obtained for the consultation step of the protocol (ethics board of the Centre intégré universitaire en santé et services sociaux de la Capitale Nationale, project \#2019-1753). The Preferred Reporting Items for Systematic Reviews and Meta-Analyses Protocols checklist will be used to support transparency and guide translation of findings. Findings will be shared with various stakeholders involved in older workers' health. Findings will also be disseminated in workshops, peer-reviewed journals and conferences.

\section{INTRODUCTION}

In Canada, it is estimated that $22 \%$ of retirees return to work after their first retirement from a paid employment. ${ }^{1}$ In the USA, more than $30 \%$ of retirees aged 50-70 want to return to the labour market and have a 'second career'. ${ }^{2}$ Whether it is for financial reasons or for personal satisfaction, ${ }^{1-3}$ retirees returning to work are more and more numerous. This trend appears to be increasing since $13.9 \%$ of the labour force was aged 65 and over in 2006 , compared with $8.4 \%$ in $2001 .{ }^{4}$ Although this increase is present among all older workers (The term « older workers » refers to workers aged 55 years and over who keep on working, including retirees who return to work after their first retirement.), ${ }^{4}$ it appears to be more pronounced for educated retirees and

\section{Strengths and limitations of this study}

No previous study has systematically mapped how returning to work after retirement does influence older workers' health, which is a relevant and emerging topic in modern societies.

- This study protocol integrates seven systematic steps and formalises the transfer knowledge activities.

- Analysis of literature data will be based on an internationally recognised framework, the International Classification of Functioning, Disability and Health.

- To capture the full range of evidence, the review will include all types of documents (eg, scientific articles, book chapters, theses, web pages) related to the topic.

- Consistent with the scoping review design, quality assessment and grading of retained documents will not be performed.

especially for men. ${ }^{3} 4$ Those who decide to return to work mostly took their first retirement around the age of 53.3 years. ${ }^{3}$ While the majority of employed retirees work parttime, $30 \%$ work full-time. ${ }^{4}$ In addition, $50 \%$ of them do so in a different company than where they retired. Finally, $40 \%$ work in a totally different occupation than the former, that requires different skills and training. ${ }^{5}$

Individual studies about the influence of work on older workers' health report inconsistent results. Indeed, some suggest positive effects of work on their health status because it acts as a protection against cognitive decline. ${ }^{6}$ In addition, work as a source of recognition and a way to contribute to society would have a positive impact on the psychological health of older workers. ${ }^{78}$ Others suggest that older workers are less at risk of injuries than younger workers because of the experience they have acquired, which is preventive. ${ }^{9}$ On the contrary, some authors have highlighted the negative effects of work on older workers' health. For example, the number of occupational diseases (eg, ear or upper limb problems) doubled between 2002 
and 2011 among workers aged 55 and over. ${ }^{10}$ In the same period, workplace accidents increased by $16 \%$ among this population. ${ }^{10}$ It seems the severity of the injuries suffered by these workers would be higher, often resulting in a prolonged absence from work and a longer recovery time. ${ }^{10-12}$ Another negative impact for older workers is that they may face employment stigma, either from younger colleagues or the employer..$^{13}{ }^{14}$ For example, older workers have difficulty accessing adequate and sufficient training, ${ }^{15}$ mostly because employers perceive them as less suitable for training due to a presumed decline in their learning abilities. ${ }^{16}$ This can lead to difficulties in completing the work required and undermining confidence in their abilities. ${ }^{17}$ Finally, other authors suggest that working at an advanced age would have no influence on health, neither positive nor negative. ${ }^{18}$ In short, further work is required to understand how work affects older workers' health.

Since many retirees decide to return to work in a different occupation than the former, they may have to live with the issues of working in a new occupation. Indeed, inexperience in an occupation acts as a risk factor for their health status, despite workers' age. The relative risk of suffering a work-related injury is four times higher among new hires (ie, less than 1 month at the occupation) than employees with more than 1 year of service. ${ }^{19}$ This risk would increase with age. In fact, while the relative risk of injury is 2.84 during the first month of employment for workers aged 20-24, it rises to 4.89 for workers aged 45 and over. ${ }^{19}$ Although retirees have many years of work experience, it is not possible to avoid the challenges of having a new occupation, especially if the occupation requires skills that are different from those previously acquired.

Retirees returning to work are exposed both to the effects of working at an advanced age and to the factors associated with being employed in a new occupation. This emerging situation is not without having an impact on health, whether it is positive or negative. In this sense, it is legitimate to question the influence of returning to work after retirement on older workers' health. Therefore, we propose using a scoping review as a systematic approach to address this topic of interest. As little information is available in the literature on this subject, this study will benefit various stakeholders, such as workers themselves, work organisations, health professionals and policy makers. This paper sets out the rational and methodological protocol that underlie the proposed study.

\section{Conceptual framework}

The International Classification of Functioning, Disability and Health (ICF) has been published in 2001 by the WHO. ${ }^{20}$ ICF proposes a framework to describe health and health-related states, such as labour. At the end of the 20th century, the development of the ICF was motivated in response to various gaps identified in the biomedical models that existed then. ${ }^{21}$ Among other things, few models allowed to understand how the environment influences the functioning and health of people. Thus, the ICF was described as a biopsychosocial model allowing drawing links between (1) health condition of people (2) their functioning, in work for example, and (3) their contextual factors, such as ageing or work environment. In fact, ICF allows to take into account and to make relations between the several factors influencing health, whether they are risks, protective factors or consequences. ${ }^{20}$ ICF describes labour as a type of participation, which means an involvement in a life situation and it recognises that people's health is influenced by their life situations. Some shortcomings have although been reported in the last years concerning the use of the ICF. For example, ICF claims to be a biopsychosocial model but lacks theoretical clarity regarding that status, being still mostly anchored in a medical model..$^{22}$ Some authors have also criticised the lack of consideration for the subjective dimension in the model. Indeed, the ICF does not consider the perception of individuals about their state of health or functioning. ${ }^{23}$ Despite theses remaining gaps, ICF appears to be a holistic and global framework helpful to describe how returning to work after retirement may influence older workers' health. As it is recognised to propose a standard language, ${ }^{20}$ the use of the ICF to structure this scoping review will enable health professionals, researchers, policy makers and general public to communicate using a shared understanding and a common language surrounding the field of functioning, disability and health of older workers. Finally, ICF has been found useful in other recent scoping reviews related to health. ${ }^{24} 25$

Based on the ICF, the aim of this study is to document the influence of returning to work after retirement on older workers' health.

\section{METHOD AND ANALYSIS \\ Design}

While several review approaches do exist, a scoping review is chosen because it specifically examines the amount, range and nature of empirical and conceptual literature about a topic. ${ }^{26-28}$ It systematically maps literature to identify what is known and not known on a topic, helping to guide new research projects. It is also a useful design to organise published information. The scoping review design of Arksey and O'Malley, ${ }^{28}$ including the recommendations of Levac et $a l^{29}$ and Daudt $e t a l^{00}$ will be used. Various authors suggested using these recommendations to improve the original design of Arksey and O'Malley. ${ }^{24}{ }^{27}$ To increase scientific rigour of the protocol, the Preferred Reporting Items for Systematic Reviews and Meta-Analyses Protocols (PRISMA-P) recommendations ${ }^{31}$ will also be included, although they are traditionally applied to systematic review protocols.

\section{Procedure and analysis}

The study design proposes seven systematic steps to conduct a scientifically rigorous scoping review (see 


\begin{tabular}{ll}
\hline Table 1 & Systematic steps of the study design \\
\hline Step 1 & Identify the research question \\
Step 2 & Select relevant documents \\
Step 3 & Study the selection \\
Step 4 & Extract and chart data \\
Step 5 & Review, summarise and report results \\
Step 6 & Consult \\
Step 7 & Transfer knowledge \\
\hline
\end{tabular}

table 1). The expected duration of this study is 12 months, beginning in late summer 2018.

\section{Identify the research question}

The question should be broad and open to include as many relevant documents as possible. However, the population, goals and important concepts must be specified. The primary target question for this study is: How does returning to work after retirement influence older workers' health? The question may include all factors that can influence health, whether they are positive or negative, work or non-work related. Given the exploratory nature of the scoping review, the question could be refined or nuanced as authors review the literature.

\section{Select relevant documents}

The subject of study joins different areas of interest such as ergonomics, management, psychology and gerontology. To provide a comprehensive portrait of a multidisciplinary literature, the research strategy should be broad and inclusive. In doing so, different combinations of keywords related to the research question will allow to search for documents from the relevant databases (see table 2). In the event that an unreasonable amount of non-relevant documents are found, the search strategy would be re-evaluated and modified accordingly. To ensure literature saturation, the reference lists of the selected documents will also be examined manually. Finally, the grey literature will be explored. A search in Google with keywords similar to those used for the

\begin{tabular}{|c|c|}
\hline $\begin{array}{l}\text { Keywords (and French } \\
\text { equivalences)* }\end{array}$ & Databases and search engines \\
\hline $\begin{array}{l}\text { elder, elderly, retire, 'older } \\
\text { worker', 'senior worker', work, } \\
\text { 'return to work', re-entry, } \\
\text { labour market, job, 'bridge } \\
\text { employment’’, health, risk, } \\
\text { consequence }\end{array}$ & $\begin{array}{l}\text { MEDLINE, Embase, CINAHL, } \\
\text { Scopus, PsycINFO, ERIC, } \\
\text { Ergonomics Abstracts, Ageline, } \\
\text { Academic Search Complete, } \\
\text { Web of Science, Cochrane } \\
\text { Database of Systematic } \\
\text { Reviews, Proquest, Google } \\
\text { Scholar }\end{array}$ \\
\hline
\end{tabular}

*Terms will be searched in titles, abstracts and keywords fields of each database. Each keyword will be searched both in its singular and plural form. Multiple combinations of keywords will be used. †'Bridge employment' refers to any paid work after an individual retires or starts receiving a pension. ${ }^{38}$ scientific databases will be performed. The results generated in the first four pages will be explored. ${ }^{24}$ Since the research theme is emerging, no publication date limits the search. Two research assistants, supervised by the first author, will conduct the literature search. Finally, a librarian specialised in the field of work will be consulted. For feasibility reasons, only English and French literature will be retained.

\section{Study the selection}

The following inclusion criteria will be followed to select relevant documents: (1) documents dealing with retirees returning to work after retirement (full-time or part-time), and (2) documents addressing the concept of health. According to the WHO definition of health, ${ }^{32}$ documents dealing only with financial health will be excluded from the analysis. Following the initial analysis, these criteria could be modified by the research team to find documents that answer best the research question. First, the selected documents will be integrated into a reference management software (ie, Endnote ${ }^{33}$ ). After the elimination of duplicates, two research assistants and the first author will separately screen the relevance of all documents based on the title, abstract and keywords. If an ambiguity is present after reading these elements, the document will be read entirely to determine its inclusion in the study. Regular peer-debriefing meetings between the evaluators will take place in order to rule on the inclusion or rejection of documents in the study. ${ }^{34}$ This regular communication between evaluators heightened their reflexivity and guarded against undue influence of any one person's perspective. Inter-rater agreement will be calculated regularly throughout the study selection process in order to ensure acceptable values. ${ }^{35}$

\section{Extract and chart data}

Data on retained documents will be classified according to the characteristics of the ICF. Indeed, an extraction grid will be specifically designed for this study and validated by two experts in the field of older workers' health. The extraction grid will include various descriptive information about the study (eg, authors, funding sources), as well as methodological information (eg, participants, study design) and results (eg, outcomes on health and participation). This grid will be used by the two research assistants and the first author to extract information from five documents. Subsequently, a peer-debriefing meeting will take place between the evaluators to modify or adjust the grid as needed. These validation steps will allow to obtain the final version of the grid, which will be used for the study. Subsequently, the two research assistants will retrieve information from subsequent documents using this grid.

\section{Review, summarise and report results}

Gathering, analysing and reporting results is the crux of a scoping review so that results can have tangible implications for the society. ${ }^{26}$ In this sense, the identification 
of key themes and gaps in the state of knowledge is the main goal of this step. First, data analysis will begin with descriptive statistics (eg, number of documents retained, years of publication). ${ }^{27} 2830$ In addition, a PRISMA-P flow chart will illustrate the flow of the review process, with the included and excluded references at each step. Second, a thematic analysis ${ }^{36}$ using the ICF as a basis will enable to group data of the retained documents by meaning and to classify data into defined themes. Links between themes will be dressed to bring out similarities and differences in relation with health of retirees who returned in employment. Based on the ICF, knowledge gaps will be identified. The two research assistants, supervised by the first author, will conduct this step. Results of the scoping review will be then presented quantitatively and qualitatively, allowing a faithful overview of the literature.

\section{Consult}

A consultation team formed of different stakeholders will be put in place. The team will comprise older workers, human resource managers, ergonomists, occupational physicians and researchers in the field of occupational health. The consultation will take the form of a focus group. ${ }^{37}$ Each participant will bring a unique expertise that will enrich the perspectives of analysis of the topic. The purpose of the consultation is to verify the applicability of the results obtained, the relevance with the current work context as well as the validity of the content. This consultation step will also provide nuances to the data collected based on users' experience. Study results will be improved.

\section{Transfer knowledge}

Although this practice is not widespread in the scoping review protocols published to date, we propose to add a seventh step to the research design to structure knowledge transfer activities. Several scoping reviews report knowledge transfer activities inconsistently and in little detail in their protocol. To increase the scope of the study results, we find important to formalise this important step. Results of this study will generate new knowledge related to the health of retirees who return to work. It is then important to disseminate the results to the knowledge users. To this end, in addition to the publication of one scientific article and to the holding of scientific papers, methods that are more accessible will be used. First, a workshop for older workers will be developed and implemented in collaboration with local employment centres and an association of elderly people. Also, a popular article will be written and submitted to a consumer magazine for workers. Awareness training will also be developed and offered to human resource managers. Finally, representations will be made to the government authorities responsible for occupational injuries in Canada. All these modalities of knowledge transfer will be submitted to the consultation team for validation.

\section{Patient and public involvement}

Various stakeholders will be involved in a crucial step of the study, namely the consultation. This research step will allow to include the perceptions and experiences of relevant stakeholders in the interpretation of results. This will also be a first occasion to start disseminating findings. Following that, diverse activities also validated with stakeholders will take place to transfer knowledge.

\section{CONCLUSION}

The scoping review proposed in this protocol will synthesise knowledge to foster development of practices to preserve health of the emerging population of retirees returning to work. To our knowledge, this scoping review protocol is the first on this topic. The analysis through the ICF will enable to identify key themes and gaps existing in literature. By bringing together various sources of knowledge, this study will also allow to identify areas in which scientific evidence is currently insufficient and for which research is needed. This meaningful synthesis of literature is a first step in the development of new evidencebased practices enabling to preserve older workers' health. Finally, the proposed seven-step systematic scoping review method, including stakeholders' consultation and knowledge transfer activities, will be tested in this study, contributing to the advancement of knowledge in the methodological field of literature reviews.

Contributors AL drafted the manuscript. M-ML drafted the abstract and proposed modifications to the manuscript. AN read and improved the manuscript. RR realised the literature search required to define the problematic and to design the study. All authors approved the final version of the manuscript.

Funding This study is supported by first author's Fonds d'établissement de jeune chercheur from the Center for Interdisciplinary Research in Rehabilitation and Social Integration.

\section{Competing interests None declared.}

\section{Patient consent for publication Not required.}

Ethics approval Institutional ethics approval is unnecessary for the secondary analysis of published literature. Although an ethics certification for the consultation step of the project, which deals with human participants, has been delivered by the research ethics board of the Centre intégré universitaire en santé et services sociaux de la Capitale Nationale (\#2019-1753). As the consultation will take the form of a focus group, confidentiality and respect of opinions will be a central concern and all necessary precautions will be taken.

Provenance and peer review Not commissioned; externally peer reviewed.

Open access This is an open access article distributed in accordance with the Creative Commons Attribution Non Commercial (CC BY-NC 4.0) license, which permits others to distribute, remix, adapt, build upon this work non-commercially, and license their derivative works on different terms, provided the original work is properly cited, appropriate credit is given, any changes made indicated, and the use is non-commercial. See: http://creativecommons.org/licenses/by-nc/4.0/.

\section{REFERENCES}

1. Schellenberg G, Turcotte $M$, Ram $B$. Le travail après la retraite. L'emploi et le revenu en perspective. Ottawa, 2005:15-19.

2. Princeton Survey Research Associates International. Ventures MFC, ed. New face of work survey. San Francisco, 2005.

3. Park J. Retraite, santé et emploi chez les personnes de 55 ans et plus. L'emploi et le revenu en perspective. Ottawa, 2011:3-14. 
4. Statistiques Canada. Census in brief: working seniors in Canada. Ottawa, 2017.

5. Society of Actuaries. Key findings and issues: Working in Retirement, 2012.

6. Bosma H, van Boxtel MPJ, Ponds RWHM, et al. Education and agerelated cognitive decline: the contribution of mental workload. Educ Gerontol 2003;29:165-73.

7. Bertrand F, Hansez I, Peters S. Maintien dans I'emploi des travailleurs âgés: enjeux et pistes de travail pour les entreprises. Médecine du travail et ergonomie 2005;42:83.

8. Nogues S, Tremblay D-G. Les travailleurs en emploi post-retraite au québec: qui sont-ils? Cahiers du CIRTES, 2017.

9. Laflamme L, Menckel E, Lundholm L. The age-related risk of occupational accidents: the case of Swedish iron-ore miners. Accid Anal Prev 1996;28:349-57.

10. CNESST. Portrait des lésions professionnelles chez les travailleurs de 55 ans et plus, 2002-2011. Québec 2014;40.

11. Prud'homme P, Duguay P, Busque M-A. Indicateurs de lésions professionnelles selon l'âge. Institut de recherche Robert-Sauvé en santé et en sécurité du travail. Montréal: IRSST, 2015

12. Rogers E, Injuries WWJ. Injuries, illnesses, and fatalities among older workers. Monthly Labor Review 2005;128:24-30.

13. Harris K, Krygsman S, Waschenko J, et al. Ageism and the older worker: a scoping review. Gerontologist 2018;58:e1.

14. , Demers G. Le vieillissement de la main-d'oeuvre et l'avenir des retraités des enjeux pour tous, un effort de chacun: rapport. Québec: Ministère de l'emploi et de la solidarité sociale, 2011.

15. Statistics Canada. Formation liée à l'emploi chez les travailleurs âgés. Canada, 2012.

16. Cully M, Heuvel AV, Curtain R, et al. Participation in, and barriers to, training: the experience of older adults. Australas J Ageing 2000;19:172-9.

17. Lesemann F. La gestion des âges et la gestion du travail. Tremblay D-G, ed. D'une culture de retraite vers un nouveau management des âges et des temps sociaux. Québec : Presses de I'Université du Québec, 2007.

18. Forbes MK, Spence KM, Wuthrich VM, et al. Mental health and wellbeing of older workers in Australia. Work, Aging and Retirement 2015;1:202-13.

19. Breslin FC, Smith P. Trial by fire: a multivariate examination of the relation between job tenure and work injuries. Occup Environ Med 2006;63:27-32

20. OMS. Classification internationale du fonctionnement, du handicap et de la santé: CIF. Genève: Organisation mondiale de la santé, 2001.

21. Hemmingsson $\mathrm{H}$, Jonsson $\mathrm{H}$. An occupational perspective on the concept of participation in the International Classification of
Functioning, Disability and Health-some critical remarks. Am J Occup Ther 2005;59:569-76.

22. Imrie R. Demystifying disability: a review of the international classification of functioning, disability and health. Sociol Health IIIn 2004;26:287-305.

23. Ueda S, Okawa Y. The subjective dimension of functioning and disability: what is it and what is it for? Disabil Rehabil 2003;25:596-601.

24. Esmail A, Poncet F, Rochette A, et al. The role of clothing in participation of persons with a physical disability: a scoping review protocol. BMJ Open 2018;8:e020299.

25. Viscogliosi $\mathrm{C}$, Asselin $\mathrm{H}$, Basile $\mathrm{S}$, et al. A scoping review protocol on social participation of indigenous elders, intergenerational solidarity and their influence on individual and community wellness. BMJ Open 2017;7:e015931.

26. Levac D, Colquhoun H, O'Brien KK. Scoping studies: advancing the methodology. Implementation Science 2010;5:69.

27. Colquhoun HL, Levac D, O'Brien KK, et al. Scoping reviews: time for clarity in definition, methods, and reporting. $J$ Clin Epidemiol 2014;67:1291-4.

28. Arksey H, O'Malley L. Scoping studies: towards a methodological framework. Int J Soc Res Methodol 2005;8:19-32.

29. Levac D, Colquhoun H, O'Brien KK. Scoping studies: advancing the methodology. Implement Sci 2010;5:69.

30. Daudt HM, van Mossel C, Scott SJ. Enhancing the scoping study methodology: a large, inter-professional team's experience with Arksey and O'Malley's framework. BMC Med Res Methodol 2013;13:48

31. Shamseer L, Moher D, Clarke M, et al. Preferred reporting items for systematic review and meta-analysis protocols (PRISMA-P) 2015 elaboration and explanation. BMJ 2015;349:97647.

32. OMS. Constitution de l'Organisation mondiale de la santé. Documents fondamentaux, supplément à la 45e édition. Organisation mondiale de la Santé, 2006.

33. Clarivate Analytics. EndNote X9. 2018.

34. Padgett D. Qualitative methods in social work research. Third edition Los Angeles: edSAGE, 2017.

35. Field AP. Discovering statistics using IBM SPSS statistics: and sex and drugs and rock ' $n$ ' roll. 4th edn. Los Angeles: SAGE, 2013.

36. Paillé $P$, Mucchielli $A$. L 'analyse thématique. L'analyse qualitative en sciences humaines et sociales. Paris: A. Colin, 2012:231-314.

37. Desrosiers J, Larivière N. Le groupe de discussion focalisé. In: Corbière $\mathrm{M}$, Larivière $\mathrm{N}$, Méthodes qualitatives, quantitatives et mixtes. Québec: Presses de I'Université du Québec, 2014:257-81.

38. Ruhm CJ. Bridge jobs and partial retirement. J Labor Econ 1990;8:482-501. 